Article

\title{
Investigation of Hydraulic Fracturing Crack Propagation Behavior in Multi-Layered Coal Seams
}

\author{
Shirong Cao ${ }^{1,2}$, Xiyuan $\mathrm{Li}^{3, *}$, Zhe Zhou ${ }^{1,2, * \mathbb{D}}$, Yingwei Wang ${ }^{3}$ and Hong Ding ${ }^{1,2}$ \\ 1 State Key Laboratory of Coal Mine Disaster Dynamics and Control, Chongqing University, \\ Chongqing 400044, China; Caoshirong@cqu.edu.cn (S.C.); bugcsr1@163.com (H.D.) \\ 2 School of Resources and Safety Engineering, Chongqing University, Chongqing 400044, China \\ 3 State Key Laboratory of Coking Coal Exploitation and Comprehensive Utilization, \\ Pingdingshan 467000, China; wangyingwei.w@gmail.com \\ * Correspondence: 20182002013t@cqu.edu.cn (X.L.); zhouzhe@cqu.edu.cn (Z.Z.); Tel.: +86-23-6510-6640 (Z.Z.)
}

Received: 24 December 2019; Accepted: 5 February 2020; Published: 8 February 2020

Featured Application: This study can provide guidance for coal and coalbed methane mining processes in multi-layered coal seams.

\begin{abstract}
Coalbed methane is not only a clean energy source, but also a major problem affecting the efficient production of coal mines. Hydraulic fracturing is an effective technology for enhancing the coal seam permeability to achieve the efficient extraction of methane. This study investigated the effect of a coal seam reservoir's geological factors on the initiation pressure and fracture propagation. Through theoretical analysis, a multi-layered coal seam initiation pressure calculation model was established based on the broken failure criterion of maximum tensile stress theory. Laboratory experiments were carried out to investigate the effects of the coal seam stress and coal seam dip angle on the crack initiation pressure and fracture propagation. The results reveal that the multi-layered coal seam hydraulic fracturing initiation pressure did not change with the coal seam inclination when the burial depth was the same. When the dip angle was the same, the initiation pressure linearly increased with the reservoir depth. A three-dimensional model was established to simulate the actual hydraulic fracturing crack propagation in multi-layered coal seams. The results reveal that the hydraulic crack propagated along the direction of the maximum principal stress and opened in the direction of the minimum principal stress. As the burial depth of the reservoir increased, the width of the hydraulic crack also increased. This study can provide the theoretical foundation for the effective implementation of hydraulic fracturing in multi-layered coal seams.
\end{abstract}

Keywords: hydraulic fracturing; coal seam; multi-layered coal seams; dip angle

\section{Introduction}

Nowadays, methane is the main threat to the increase of productivity in the coal industry [1]. The high gas pressure in coal seams may lead to coal and gas outburst accidents [2]. The rational use of methane is as efficient and clean energy-coalbed methane (CBM), which mainly contains methane and is an economical and promising solution for the global energy crisis [3]. Therefore, there is an urgent need for developing CBM resources, which are abundant.

China has the most coal seams with low permeability, which make it difficult to achieve rapid extraction compared with other countries (such as Australia and the United States) [4,5]. Low permeability severely restricts the extraction of methane in coal seams and also restricts the speed of coal mining. Hydraulic fracturing is an efficient stimulation method of pressure relief and permeability enhancement for strengthening the effect of methane drainage. Moreover, hydraulic 
fracturing has been applied to coal seam pressure relief to prevent coal mine gas outburst accidents $[6,7]$. Presently, existing research on hydraulic fracturing in coal mines mainly concerns on-site practical applications. The occurrence of coal seams in different mines is variable, and a single theory cannot explain the complicated and variable coal seam hydraulic fracturing process.

Researchers have investigated theoretical and technological approaches toward enhancing the permeability of coal seams. In the last century, researchers proposed the theory of tensile failure induced by hydraulic fracturing caused by stress concentration in the wall. The analysis of the circumferential tensile stress of the borehole wall has indicated that the circumferential tensile stress of the borehole wall increases with the liquid pressure in the wellbore. The cracks initiate when the tensile stress exceeds the tensile strength of the hole wall rock [8-10]. The fracture condition of the coal around the borehole wall of the horizontal bedding layer is established based on the maximum tensile stress failure criterion, and the formula for the critical value of the coal fracturing crack initiation pressure can be derived [11,12]. Several theoretical models have been proposed for predicting the fracture initiation pressure for different pore pressure conditions and rock properties $[13,14]$. Through hydraulic fracturing experiments in soft rock, it has been found that the confining pressure and fracturing fluid properties determine the effect of hydraulic fracturing [15]. Many factors such as high injection pressure exert a certain influence on the hydraulic fracturing efficiency [16]. The influence of the pre-fracture shear strength on the propagation of hydraulic fracture was investigated [17]. Over the past decades, considerable research effort has been directed toward investigating the mechanics of hydraulic fracturing [18]. Computer simulation technology has been used to simulate hydraulic fracturing in coal seams [19-21]. For example, the effect of natural fractures on hydraulic fracturing has been investigated by analyzing the characteristics of the crack radius, crack number, and growth rate of cracks versus the injection time using PFC2D [22].

Hydraulic fracturing technology of inclined coal seams has been extensively investigated, and many theories of hydraulic fracturing initiation have guided the safe production of coal mines, which effectively supports economic development. Zhang studied the effect of the maximum principal stress or intermediate principal stress on initiation and propagation of fractures [23]. The borehole stress has been analyzed through coordinate transformation, revealing the initiation pressure, initiation location, and initiation direction of inclined well [24,25]. The crack initiation mechanism of penetrating boreholes in vertical seams was studied by analyzing the horizontal principal ground stresses [26]. However, many mining areas in China, such as Songzao, have multiple coal seam layers and a large burial depth and dip angle range. The crack initiation and extension law during the fracturing of these coal seams have not been clarified, which results in the uninformed selection of fracturing parameters and drilling arrangement. Drilling an inclined crossing borehole in a multi-layered coal seam and then performing hydraulic fracturing is an effective method for increasing the permeability of the abovementioned coal seams, as shown in Figure 1.

The relationship between the extended pressure with internal pressure cracks, and the original geo-stress field and mechanical properties of the surrounding rock have been obtained. The minimum fracture pressure of hydraulic fracture initiation in rock mass has also been obtained [27]. According to previous studies, the geo-stress has a controlling effect on the vertical propagation of hydraulic fractures. As the minimum horizontal principal stress of the adjacent layer increases, it is difficult for hydraulic fractures to penetrate the adjacent layers [28]. Numerical simulation based on the finite element method have been used to solve the problem of natural cracking in wellbores under different geo-stress conditions. The cracking pressure and influence of geo-stress on the cracking position have been analyzed $[29,30]$. This study mostly focused on a single coal seam, and investigated the hydraulic fracturing of coal seams under complex conditions (multi-layered and soft-layered), which has been poorly researched. 


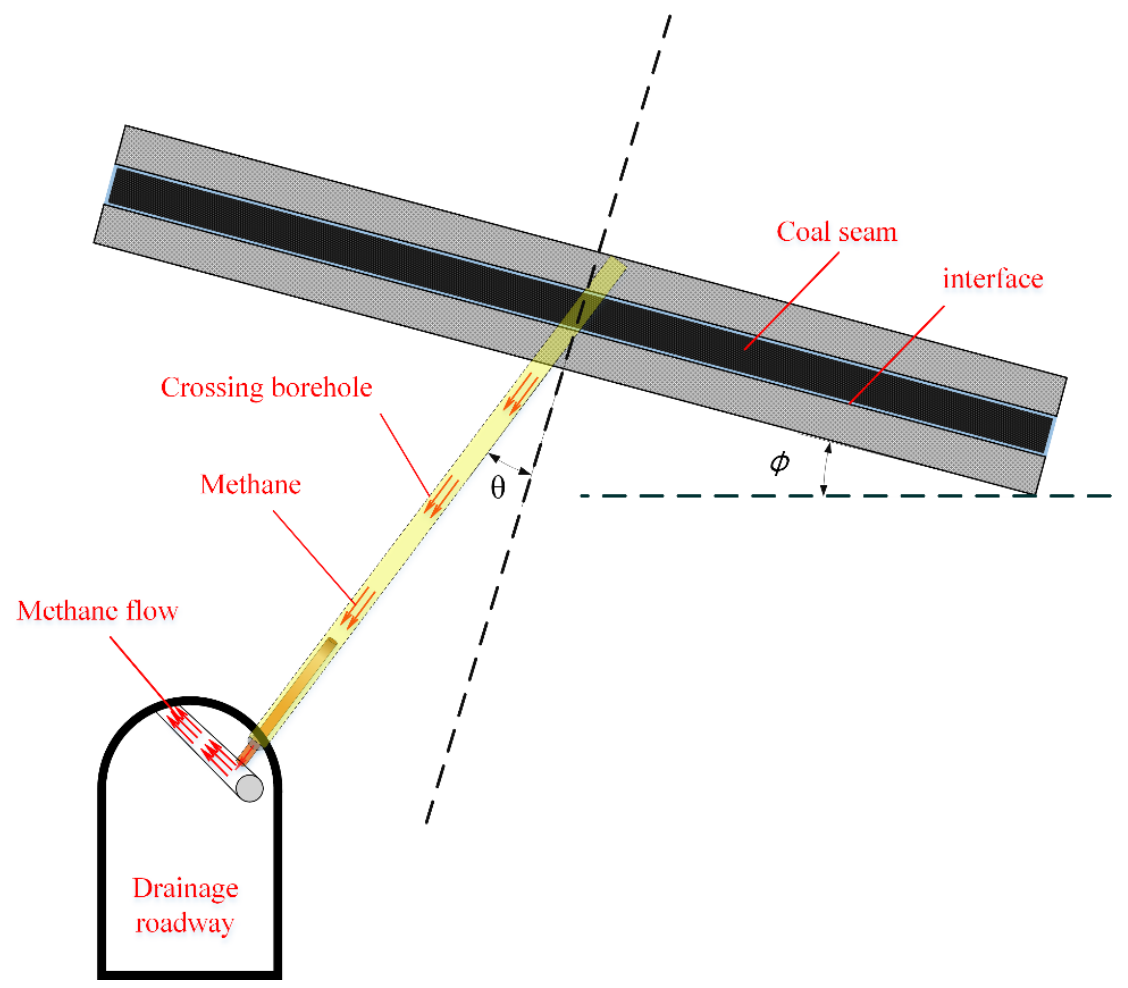

Figure 1. Relative position of crossing borehole and coal seam.

Therefore, the objective of this study was to clarify the abovementioned theoretical mechanisms. The theoretical analysis of the cracking pressure of the borehole wall in a multi-layered coal seam was carried out. The hydraulic fracture testing of the coal seam was carried out by simulating different burial depths and dips to investigate the cracking pressure, cracking position, and crack propagation of the coal seam. The results of this paper can be useful as theoretical guidelines for the development of coalbed methane in complex coal reservoirs.

\section{Analysis of Crack Initiation Pressure of Inclined Crossing Borehole Wall}

\subsection{Analysis of Stress Distribution in Inclined Borehole}

To analyze the stress of the rock surrounding an inclined borehole, it is necessary to convert the original rock stress distribution into the axial and radial stress distribution of the borehole. A coordinate system $\left(\sigma_{v}, \sigma_{H}, \sigma_{h}\right)$ consistent with the direction of the three-way principal geo-stress was established. Additionally, a Cartesian coordinate system $(x, y, z)$ was established in a section of the borehole, where the $\mathrm{Oz}$ axis corresponds to the central axis of the borehole, and Ox and Oy are located along the planes perpendicular to the central axis of the borehole. The coordinate transformation of the central axis of the borehole is shown in Figure 2. 


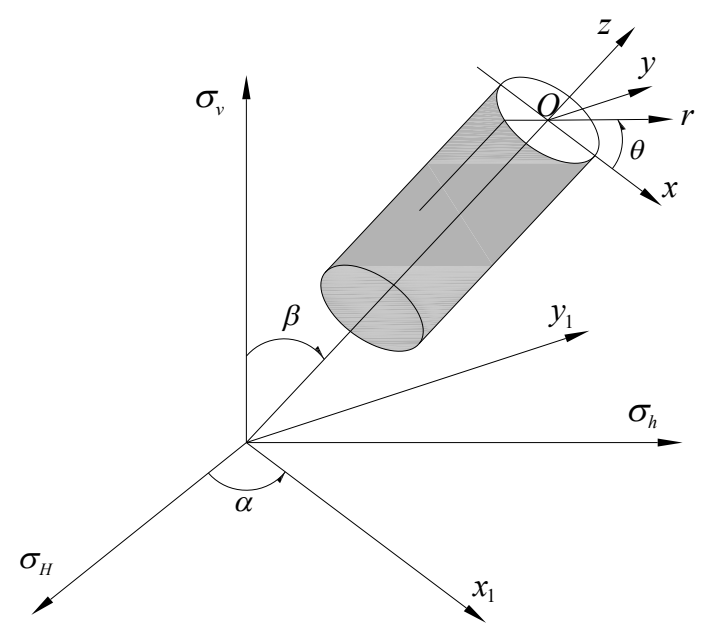

Figure 2. Coordinate transformation of drilling central axis.

According to Figure 2, after transforming the principal geo-stress system $\left(\sigma_{v}, \sigma_{H}, \sigma_{h}\right)$ into the borehole rectangular coordinate system $(x, y, z)$, the following stress transformation expression can be obtained [31]:

$$
\left\{\begin{array}{l}
\sigma_{x}=\left(\sigma_{H} \cos ^{2} \alpha+\sigma_{h} \sin ^{2} \alpha\right) \cos ^{2} \beta+\sigma_{v} \sin ^{2} \beta \\
\sigma_{y}=\sigma_{H} \sin ^{2} \alpha+\sigma_{h} \cos ^{2} \alpha \\
\sigma_{z}=\left(\sigma_{H} \cos ^{2} \alpha+\sigma_{h} \sin ^{2} \alpha\right) \sin ^{2} \beta+\sigma_{v} \cos ^{2} \beta
\end{array}\right.
$$

where $\sigma_{v}, \sigma_{H}$, and $\sigma_{h}$ are the stress components of the borehole cross-section coordinate system; $\alpha$ is the angle between the borehole azimuth and $\sigma_{H}$; and $\beta$ is the angle between the borehole center axis and $\sigma_{v}$.

\subsection{Stress Distribution of Rock Surrounding Wall of Inclined Borehole}

Presently, most coal mines use hydraulic fracturing by a crossing borehole. It is assumed that the borehole wall of the crossing borehole cracks along a certain section under the action of water injection pressure and original stress. At this time, the stress distribution of the section can be treated as a plane strain problem, as shown in Figure 3.

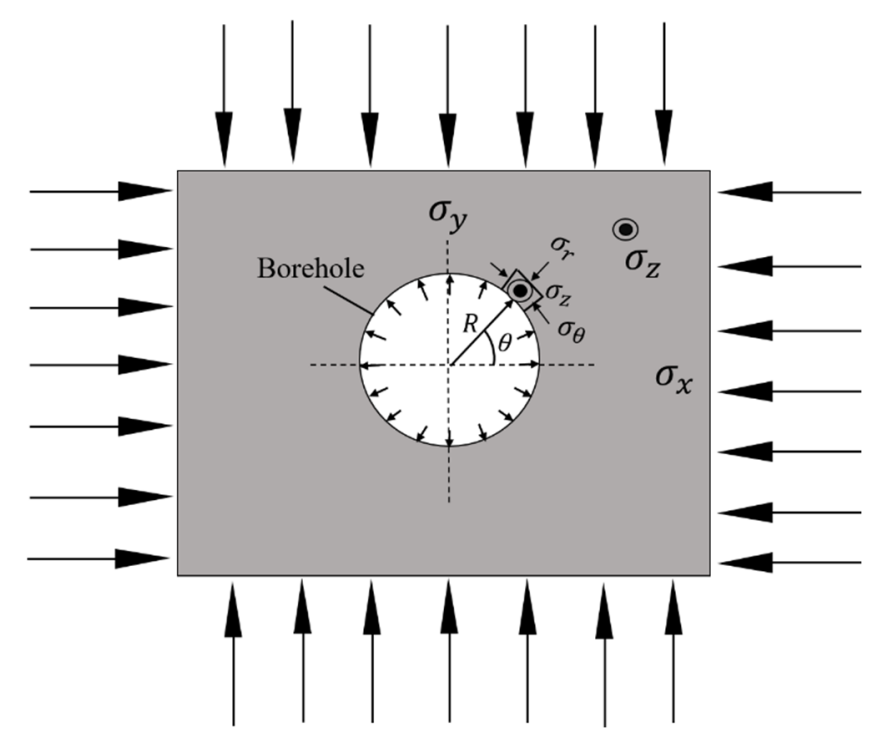

Figure 3. Radial stresses at borehole wall. 
The stress distribution can be obtained by superimposing the compressive stress in the radial direction of the borehole section and the stress component generated by the water injection pressure. The stress distribution at a certain point of the radial section of the borehole section is expressed as follows [26]:

$$
\left\{\begin{array}{l}
\sigma_{r}=\frac{\sigma_{x}+\sigma_{y}}{2}\left(1-\frac{R^{2}}{r^{2}}\right)+\frac{\sigma_{x}-\sigma_{y}}{2}\left(1-\frac{4 R^{2}}{r^{2}}+\frac{3 R^{4}}{r^{4}}\right) \cos 2 \theta+\frac{p R^{2}}{r^{2}} \\
\sigma_{\theta}=\frac{\sigma_{x}+\sigma_{y}}{2}\left(1+\frac{R^{2}}{r^{2}}\right)-\frac{\sigma_{x}-\sigma_{y}}{2}\left(1+\frac{3 R^{4}}{r^{4}}\right) \cos 2 \theta-\frac{p R^{2}}{r^{2}}
\end{array}\right.
$$

where $\sigma_{r}$ and $\sigma_{\theta}$ are the radial stresses and tangential stress at any point in the rock surrounding the borehole; $R$ is the radius of the borehole; $r$ is the distance from any point to the center of the borehole; $\theta$ is the direction angle of a certain measuring point; and $p$ is the injection pressure of water.

The stress distribution at a point along the radial surrounding rock of the borehole section under the three-way geo-stress and injection pressure of water can be obtained as follows [32]:

$$
\left\{\begin{aligned}
\sigma_{r}= & \frac{p R^{2}}{r^{2}}+\frac{\left(\sigma_{H} \cos ^{2} \alpha+\sigma_{h} \sin ^{2} \alpha\right) \cos ^{2} \beta+\sigma_{v} \sin ^{2} \beta+\sigma_{H} \sin ^{2} \alpha+\sigma_{h} \cos ^{2} \alpha}{2}\left(1-\frac{R^{2}}{r^{2}}\right) \\
& +\frac{\left(\sigma_{H} \cos ^{2} \alpha+\sigma_{h} \sin ^{2} \alpha\right) \cos ^{2} \beta+\sigma_{v} \sin ^{2} \beta-\sigma_{H} \sin ^{2} \alpha-\sigma_{h} \cos ^{2} \alpha}{2}\left(1-\frac{4 R^{2}}{r^{2}}+\frac{3 R^{4}}{r^{4}}\right) \cos 2 \theta \\
\sigma_{\theta}= & -\frac{p R^{2}}{r^{2}}+\frac{\left(\sigma_{H} \cos ^{2} \alpha+\sigma_{h} \sin ^{2} \alpha\right) \cos ^{2} \beta+\sigma_{v} \sin ^{2} \beta+\sigma_{H} \sin ^{2} \alpha+\sigma_{h} \cos ^{2} \alpha}{2}\left(1+\frac{R^{2}}{r^{2}}\right) \\
& -\frac{\left(\sigma_{H} \cos ^{2} \alpha+\sigma_{h} \sin ^{2} \alpha\right) \cos ^{2} \beta+\sigma_{v} \sin ^{2} \beta-\sigma_{H} \sin ^{2} \alpha-\sigma_{h} \cos ^{2} \alpha}{2}\left(1+\frac{3 R^{4}}{r^{4}}\right) \cos 2 \theta
\end{aligned}\right.
$$

\subsection{Analysis of Crack Initiation Pressure of Multi-Layered Coal}

Because the tensile strength of the rock mass is much smaller than the compressive strength, the failure criterion of the surrounding rock fracture of the borehole considers the maximum tensile stress theory [33]. Under the combined action of water injection pressure and geo-stress, the tensile stress generated at a certain position of the surrounding rock of the borehole exceeds the tensile strength of the rock mass, and cracking occurs. In other words, the water injection pressure needs to overcome the tangential stress of the surrounding rock when cracking occurs to avoid stretch damage to the borehole wall.

\subsubsection{Analysis of Cracking Pressure When Cracking Occurs along Radial Direction of Borehole}

The cracking of the surrounding rock starts from the wall surface of the borehole. According to Equation (3), the tangential stress along the radial wall of the borehole section under the triaxial stress and water injection pressure can be obtained, as follows:

$$
\begin{aligned}
& \sigma_{\theta}=-p+\left[\left(\sigma_{H} \cos ^{2} \alpha+\sigma_{h} \sin ^{2} \alpha\right) \cos ^{2} \beta+\sigma_{v} \sin ^{2} \beta+\sigma_{H} \sin ^{2} \alpha+\sigma_{h} \cos ^{2} \alpha\right] \\
& -2\left[\left(\sigma_{H} \cos ^{2} \alpha+\sigma_{h} \sin ^{2} \alpha\right) \cos ^{2} \beta+\sigma_{v} \sin ^{2} \beta-\sigma_{H} \sin ^{2} \alpha-\sigma_{h} \cos ^{2} \alpha\right] \cos 2 \theta
\end{aligned}
$$

It is assumed that the maximum horizontal principal stress is consistent with the coal seam tendency, while the minimum horizontal principal stress is consistent with the coal seam trend. The azimuth of the borehole is assumed to crack along the axial layer of the borehole when the coal is fractured, and the influence of the radial stress of the borehole can be ignored.

$$
\sigma_{\theta}=\left(\sigma_{H} \cos ^{2} \beta+\sigma_{v} \sin ^{2} \beta+\sigma_{h}\right)-2\left(\sigma_{H} \cos ^{2} \beta+\sigma_{v} \sin ^{2} \beta-\sigma_{h}\right) \cos 2 \theta-p
$$

When $0 \leq \theta \leq 180^{\circ}$, only $\theta=0$ and $\theta=90^{\circ}$ result in an extreme tangential stress value. Therefore, the tangential stress is considered only with the direction angle and extreme values in both cases.

$$
\left\{\begin{array}{l}
\sigma_{\theta=0}=3 \sigma_{h}-\sigma_{H} \cos ^{2} \beta-\sigma_{v} \sin ^{2} \beta-p \\
\sigma_{\theta=90}=3\left(\sigma_{H} \cos ^{2} \beta+\sigma_{v} \sin ^{2} \beta\right)-\sigma_{h}-p
\end{array}\right.
$$


For the borehole wall to crack, $\left|\sigma_{\theta}\right|>\sigma_{t}$ must be satisfied, where $\sigma_{t}$ is the tensile strength of the coal seam. Because each coal layer has a different tensile strength, $\sigma_{t i}$ is considered as the tensile strength of the $i$ th coal layer, $\min \left\{\sigma_{t i}\right\}$ is the minimum coal layer tensile strength, $1 \leq I \leq n$, and $n$ is the coal layer number. Then, the cracking pressure must satisfy the following conditions:

$$
\left\{\begin{array}{l}
p_{\theta=0}>3 \sigma_{h}-\sigma_{H} \cos ^{2} \beta-\sigma_{v} \sin ^{2} \beta+\min \left\{\sigma_{t i}\right\} \\
p_{\theta=90}>3\left(\sigma_{H} \cos ^{2} \beta+\sigma_{v} \sin ^{2} \beta\right)-\sigma_{h}+\min \left\{\sigma_{t i}\right\}
\end{array}\right.
$$

Therefore, when only the radial cracking is analyzed, the cracking pressure of the borehole wall can be expressed as follows:

$$
p_{1}=\min \left\{\begin{array}{c}
3 \sigma_{h}-\left(\sigma_{H} \cos ^{2} \beta+\sigma_{v} \sin ^{2} \beta\right)+\min \left\{\sigma_{t i}\right\}, \\
3\left(\sigma_{H} \cos ^{2} \beta+\sigma_{v} \sin ^{2} \beta\right)-\sigma_{h}+\min \left\{\sigma_{t i}\right\}
\end{array}\right\}
$$

\subsubsection{Analysis of Cracking Pressure When Cracking Occurs along Axial Direction of Borehole}

The drilling inclination angle is $\beta$, the angle between the borehole and the normal direction of the coal seam is $\gamma=\beta-\varphi$, and, according to the axial stress $\sigma_{z}$ of the borehole in Equation (1), the normal stress $P_{f}$ on the coal layer can be obtained as follows:

$$
p_{f}=\left[\left(\sigma_{H} \cos ^{2} \alpha+\sigma_{h} \sin ^{2} \alpha\right) \sin ^{2} \beta+\sigma_{v} \cos ^{2} \beta\right] \cos (\beta-\phi)
$$

When $\alpha=0$ :

$$
p_{f}=\left(\sigma_{H} \sin ^{2} \beta+\sigma_{v} \cos ^{2} \beta\right) \cos (\beta-\phi)
$$

If the coal seam fracture occurs along the axial direction of the borehole, the water injection pressure $P$ must overcome the normal stress $P_{f}$ and the cohesive force $C$ of the coal layer to cause damage to the coal layer. Let us consider $C_{i}$ as the cohesive force of the $i$ th coal layer, and $\min \left\{C_{i}\right\}$ as the minimum cohesive force between the layers, where $\mathrm{n}$ is the number of coal layers. According to Equation (10), the water injection pressure when the borehole is cracked in the axial direction can be satisfied as follows:

$$
p_{2}=\left(\sigma_{H} \sin ^{2} \beta+\sigma_{v} \cos ^{2} \beta\right) \cos (\beta-\phi)+\min \left\{C_{i}\right\}
$$

To achieve multi-layered coal cracks initiated by axial or radial cracks, different water injection pressure conditions must be satisfied. The water injection pressure calculation model of the multi-layer coal seam can be established as follows:

$$
p=\min \left\{p_{1}, p_{2}\right\}=\min \left\{\begin{array}{l}
3 \sigma_{h}-\left(\sigma_{H} \cos ^{2} \beta+\sigma_{v} \sin ^{2} \beta\right)+\min \left\{\sigma_{t i}\right\} \\
3\left(\sigma_{H} \cos ^{2} \beta+\sigma_{v} \sin ^{2} \beta\right)-\sigma_{h}+\min \left\{\sigma_{t i}\right\} \\
\left(\sigma_{H} \sin ^{2} \beta+\sigma_{v} \cos ^{2} \beta\right) \cos (\beta-\phi)+\min \left\{C_{i}\right\}
\end{array}\right\}
$$

where $\sigma_{v}$ is the vertical principal stress, $\sigma_{H}$ is the maximum horizontal principal stress, and $\sigma_{h}$ is the minimum horizontal principal stress.

From the above formula, it follows that the initiation pressure is affected by the coal seam geo-stress, dip angle, coal tensile strength, interface cohesive force, and borehole angle.

\section{Hydraulic Fracturing Experiment}

\subsection{Experimental Apparatus}

The experimental apparatus used to conduct the hydraulic fracturing simulation was a triaxial simulation system. As shown in Figure 4, the apparatus comprised a large stress loading system, pressurization system, injection system, data acquisition system, and computer control system. 


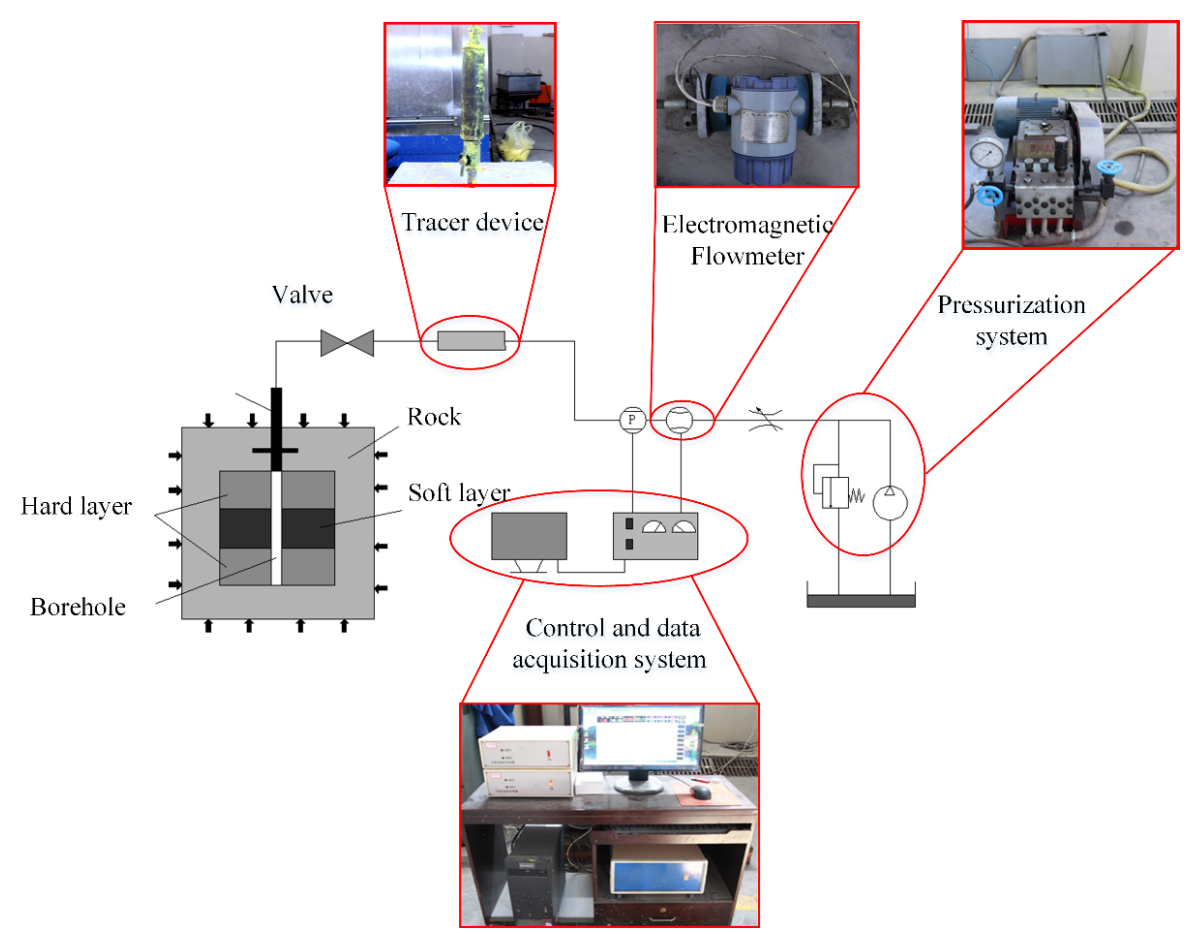

Figure 4. Hydraulic fracturing test system.

\subsection{Experimental Design}

The model was compared with the coal seam in Songzao, and the experiment was designed according to the geometric similarity, weight similarity, and geo-stress similarity; the similarity constant of stress was 7.6. The physical and mechanical properties of the experimental samples are listed in Table 1. The experimental parameters and experimental program were designed as shown in Table 2. To investigate the effects of the coal layer's depth and dip angle on the propagation of hydraulic fractures, the experimental specimens were multi-layered and in different stress states.

Table 1. Physical and mechanical properties of samples.

\begin{tabular}{ccccc}
\hline Material Name & Quality Ratio & $\begin{array}{c}\gamma \\
/ \mathbf{k N} / \mathbf{m}^{-3}\end{array}$ & $\begin{array}{c}\sigma c \\
/ \mathbf{M P a}\end{array}$ & $\begin{array}{c}\sigma t \\
/ \mathbf{M P a}\end{array}$ \\
\hline Hard layer of coal seam & Pulverized coal:cement:gypsum =3:3:1 & 1.9 & 7.01 & 0.66 \\
Soft layer of coal seam & Pulverized coal:soil =3:1 & 1.3 & 3.67 & 0.45 \\
\hline
\end{tabular}

Table 2. Hydraulic fracturing simulation experiment for multi-layered samples.

\begin{tabular}{ccccc}
\hline Number & Simulation Depth & $\sigma_{v} / \sigma_{H} / \sigma_{h} / \mathbf{M P a}$ & Coal Seam Dip/ $^{\circ}$ & Fracturing Fluid $^{\text {HPater }}$ \\
\hline \#2 & 300 & $1.07 / 1.07 / 0.64$ & 0 & Water \\
$\# 3 \mathrm{a}$ & 400 & $1.42 / 1.42 / 0.85$ & 0 & Water \\
$\# 3 \mathrm{~b}$ & 500 & $1.78 / 1.78 / 1.07$ & 0 & Water \\
$\# 3 \mathrm{c}$ & 500 & $1.78 / 1.78 / 1.07$ & 10 & Water \\
$\# 3 \mathrm{~d}$ & 500 & $1.78 / 1.78 / 1.07$ & 20 & Water \\
$\# 3 \mathrm{e}$ & 500 & $1.78 / 1.78 / 1.07$ & 30 & Water \\
$\# 3 \mathrm{f}$ & 500 & $1.78 / 1.78 / 1.07$ & 40 & Water \\
$\# 4$ & 500 & $1.78 / 1.78 / 1.07$ & 50 & Water \\
$\# 5$ & 600 & $2.13 / 2.13 / 1.28$ & 0 & Water \\
$\# 6$ & 700 & $2.49 / 2.49 / 1.49$ & 0 & Water \\
\hline
\end{tabular}




\subsection{Specimen Preparation}

Pulverized coal was collected from the M8 coal seam in the Songzao coal mine in southwest China. Multi-layered specimens with a hard layer and soft layer and different component ratios were made in the laboratory, as shown in Figure 5. Multi-layered coal seam specimens with different coal seam inclination angles were made. The specimen size was $300 \mathrm{~mm} \times 300 \mathrm{~mm} \times 300 \mathrm{~mm}$, and each specimen had a soft coal layer sandwiched between two hard coal layers; each layer thickness was $100 \mathrm{~mm}$. Subsequently, the steel tube was fixed to the center hole to simulate the crossing borehole. The front end of the fracturing drill pipe was connected to a screen tube such that high water pressure could be applied to the coal seam. The non-open borehole section was cemented using a specific chemical glue. The process of producing the multi-layer coal seam samples is shown in Figure 6.
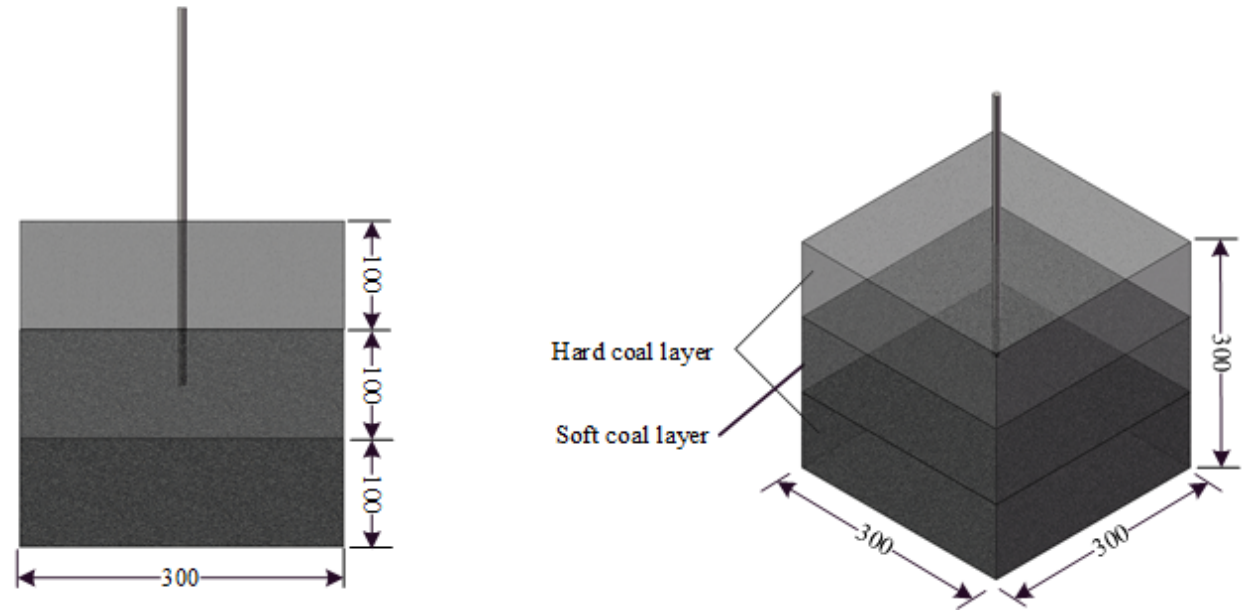

Figure 5. Specimen design.
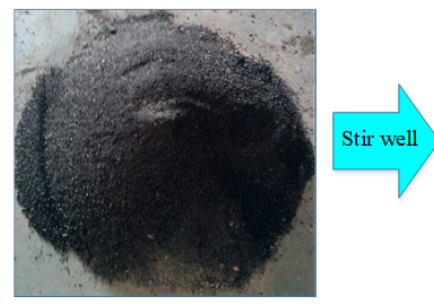
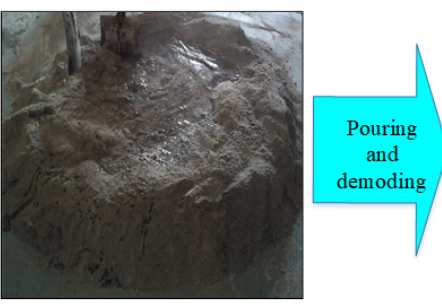

Figure 6. Specimen preparation.

\subsection{Experimental Procedure}

To simulate the process of hydraulic fracturing, the wellbore direction was vertical to the face, and at an angle to the mezzanine. To prevent the mechanical shear failure of the specimen, which is caused by triaxial stress loading, the three-dimensional stresses were simultaneously loaded. The pressure and flow data acquisition system was turned on, and the hydraulic fracturing test was initiated after the high-pressure water pump was turned on.

For convenient crack observation, a yellow agent was mixed with the fracturing fluid to enhance the detection of hydraulic fracturing. The pump was turned off when the injection pressure became stable, and the yellow agent overflowed from the specimen. At the end of the test, the specimen was removed and the crack distribution was observed after the specimen had fractured. 


\subsection{Results and Analysis}

\subsubsection{Influence of Geo-Stress on Coal Seam Hydraulic Fracturing}

The experimental results reveal that, when there existed a difference between the vertical stress and the dip angle, the initiation pressure of the coal seam was different, and the variation of water injection pressure during fracturing could approximately reflect the three stages of hydraulic fracturing, as shown in Figure 7.

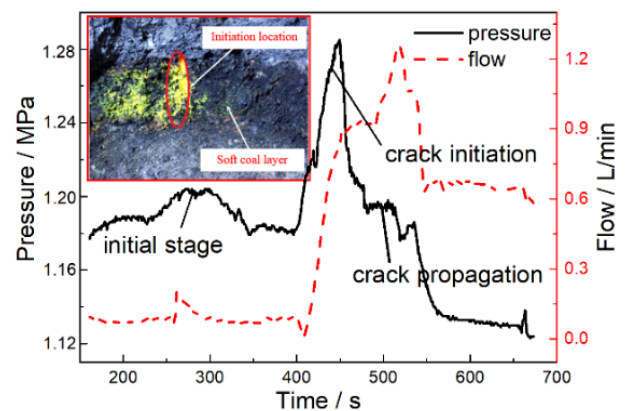

$\# 1$

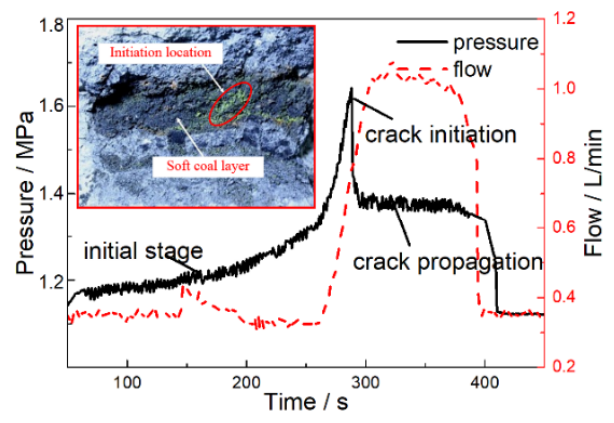

$\# 3 \mathrm{a}$

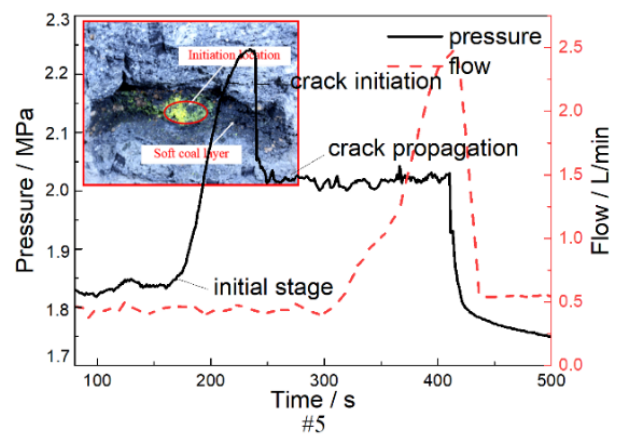

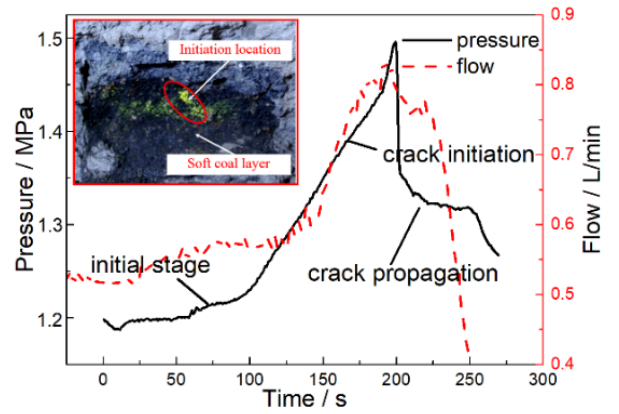

\#2

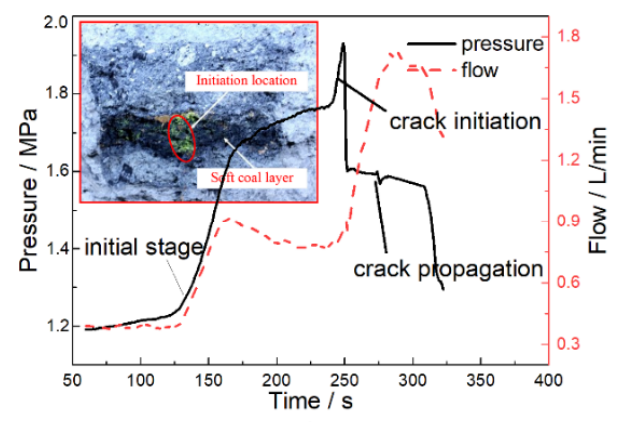

\#4

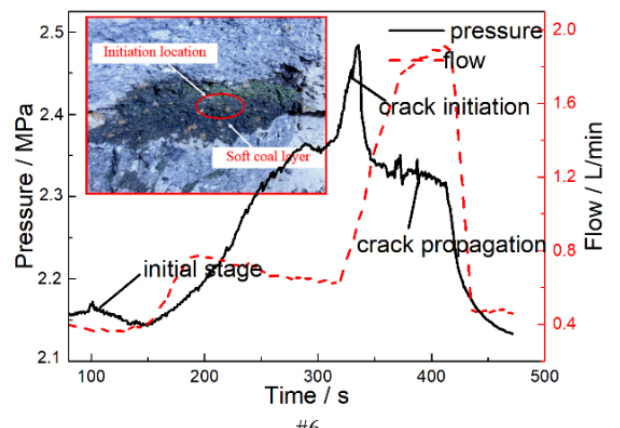

\#6

Figure 7. Pressure and flow rate under different stress.

As shown in Figure 7, the hydraulic fracturing process is divided into three processes: the initial stage, crack initiation, and crack propagation. In the initial stage of hydraulic fracturing, that is, in the stress accumulation stage, the water injection pressure and flow rate slightly and steadily increased. When the stress of the borehole wall reached a certain value, the water injection pressure rapidly increased and reached the peak value. At this time, the tangential stress, which was formed by the water injection pressure around the borehole wall, was greater than the tensile strength of the multi-layered coal seams, and the original gap in the coal seam opened to form the initial crack. The initial cracks penetrated each other under the action of water pressure. At this stage, a fracture started forming in the coal seam, and the flow rapidly increased to the peak flow. The deepest part of the tracer color in the figure indicates the cracking location. In the stage of crack propagation, as the water injection was filled again while the crack had formed in the coal seam, the crack continued to expand and formed a through fracture. 
The cracking location of a multi-layer coal seam is always in the soft layer under different stress states. In the test, the angle between the fracture hole and the vertical direction was zero, and the tensile strength $\sigma_{t i}$ of each coal was obtained through experiments. The cohesion force $C_{i}$ was selected according to the existing test data. According to Equation (12), the initiation pressure of coal fracturing was theoretically calculated, as shown in Figure 8. In multi-layer coal seams, the in-situ stress has an effect on hydraulic fracturing. As the depth and stress increase, the cracking pressure of the multi-layer coal seam increases in an approximately linear manner. The experimental results and theoretical calculation results are in good agreement.

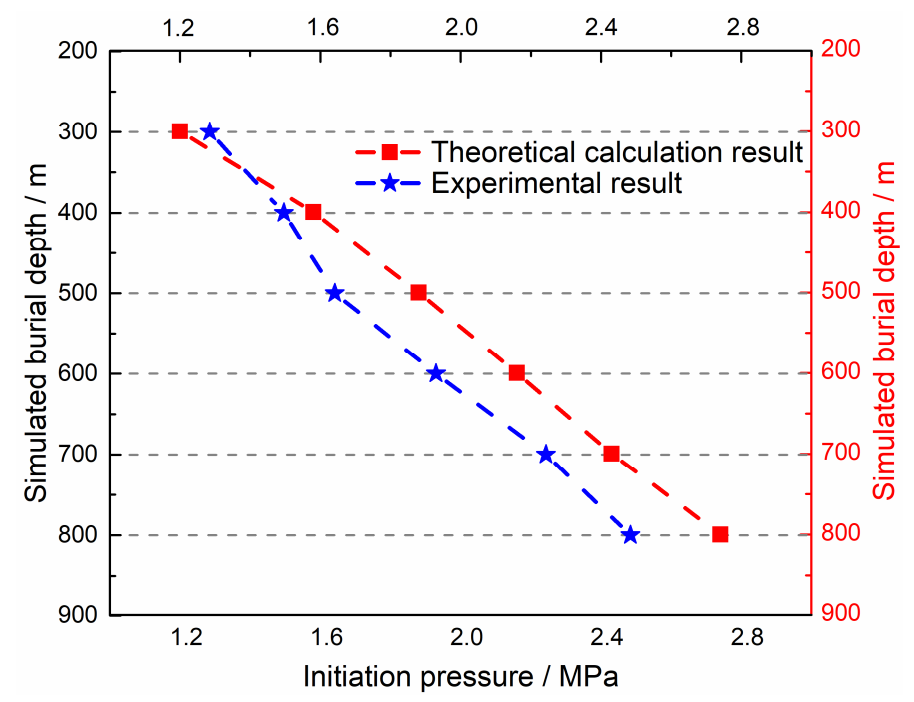

Figure 8. Initiation pressure with different burial depths.

\subsubsection{Influence of Coal Seam Dip Angle on Hydraulic Fracturing}

Five types of typical multi-layer coal seam specimens were used in the hydraulic fracturing experiment. The crack initiation pressure and initiation location were recorded as they evolved with time. Moreover, the theoretical calculation results for the initiation pressure with different coal seam dips was obtained (Figure 9) using Equation (12). Thus, the evolution of the crack initiation pressure and crack initiation location can be observed for different coal seam dip angles.

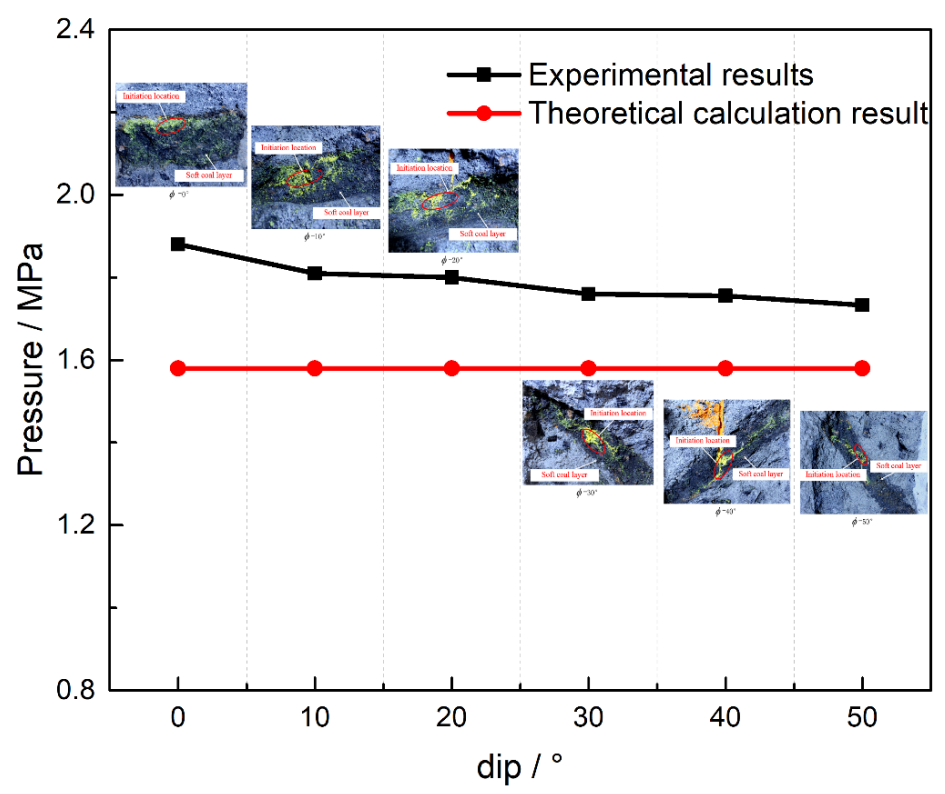

Figure 9. Initiation pressure with different coal seam dips. 
As can be seen in Figure 9, the theoretical and actual crack initiation pressures hardly changed with the dip angle of the coal seam in the coal seam inclination range $\left(0-50^{\circ}\right)$. The network crack was formed in the near horizontal coal seam, and an obvious main crack did not exist. In the inclined coal seam, an obvious main crack could easily form. As the dip angle increased, the network crack around the main crack gradually decreased.

\section{Three-Dimensional Numerical Simulation of Hydraulic Fracturing}

This paper proposes a three-dimensional finite element model. Factors such as the in-situ stress, initial coal seam status, initial fluid density, and fluid leaking were considered. Additionally, the process of hydraulic fracturing in multi-layer coal seams was simulated with consideration to different depths.

\subsection{Simulation Model and Parameters}

A three-dimensional model was constructed to simulate the true hydraulic fracturing of multi-layered coal seams in coal mines using the ABAQUS finite element software. Figure 10 shows the schematic of the 3D model. The dimensions of the model were $60 \mathrm{~m}, 50 \mathrm{~m}$, and $100 \mathrm{~m}$ in the $X, Y$, and $Z$ direction, respectively. The hard coal layer and soft coal layer were assumed to be fully bonded. Two potential fracture propagation faces with cohesive unit properties were set to observe the interaction between the adjacent hard and soft layer hydraulic fractures [34]. The maximum principal stress occurred along the $X$ direction, while the minimum principal stress occurred along the $Z$ direction. The initiating point was located at the center of the coal seam. To improve the accuracy of the simulation results, local grid refinement was carried out to define the grids of the hydraulic fractures and multi-layered coal seams. The parameters used in the model are listed in Table 3.

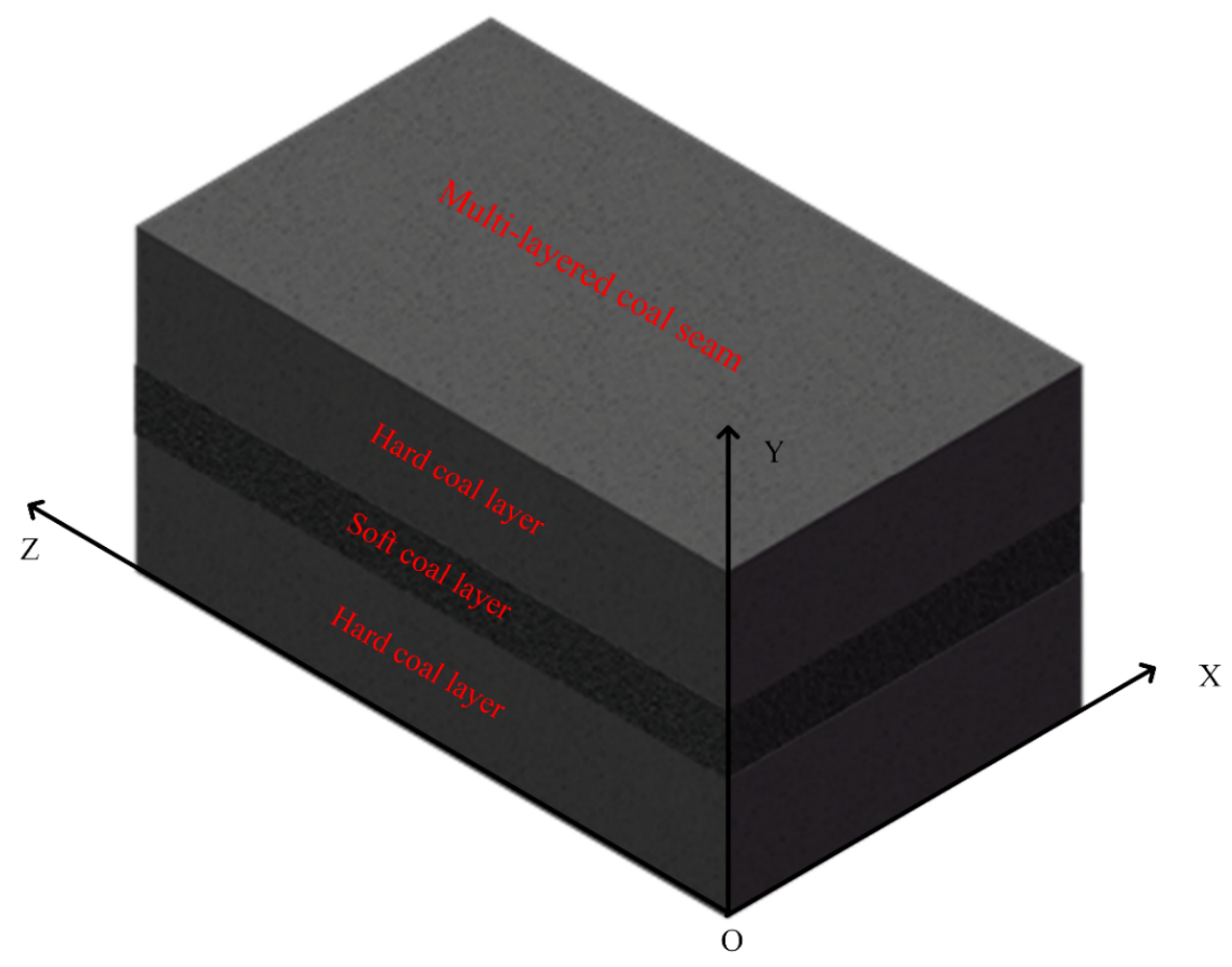

Figure 10. Model sketch. 
Table 3. Model parameters.

\begin{tabular}{cccc}
\hline Items & Unit & Hard Coal Layer & Soft Coal Layer \\
\hline Elastic modulus & $\mathrm{GPa}$ & 2.2 & 0.4 \\
\hline Poisson's ratio & & 0.39 & 0.15 \\
\hline Geo-stress $\sigma \mathrm{x} / \sigma \mathrm{y} / \sigma \mathrm{z}(300 \mathrm{~m})$ & & $5 / 8 / 10$ & $5 / 8 / 10$ \\
Geo-stress $\sigma \mathrm{x} / \sigma \mathrm{y} / \sigma \mathrm{z}(400 \mathrm{~m})$ & & $7 / 11 / 13$ & $7 / 11 / 13$ \\
Geo-stress $\sigma \mathrm{x} / \sigma \mathrm{y} / \sigma \mathrm{z}(500 \mathrm{~m})$ & $\mathrm{MPa}$ & $8 / 13 / 15$ & $8 / 13 / 15$ \\
Geo-stress $\sigma \mathrm{x} / \sigma \mathrm{y} / \sigma \mathrm{z}(600 \mathrm{~m})$ & & $10 / 16 / 18$ & $10 / 16 / 18$ \\
Geo-stress $\sigma \mathrm{x} / \sigma \mathrm{y} / \sigma \mathrm{z}(700 \mathrm{~m})$ & & $13 / 19 / 21$ & $13 / 19 / 21$ \\
Geo-stress $\sigma \mathrm{x} / \sigma \mathrm{y} / \sigma \mathrm{z}(800 \mathrm{~m})$ & & $15 / 21 / 23$ & $15 / 21 / 23$ \\
\hline Permeability coefficient & $\mathrm{m} / \mathrm{s}$ & $1 \times 10^{-7}$ & $1 \times 10^{-7}$ \\
\hline Fluid leak off & & $1 \times 10^{-14}$ & $1 \times 10^{-14}$ \\
\hline Pore ratio & & 0.2 & 0.2 \\
\hline Fluid gravity & $\mathrm{N} / \mathrm{m}^{3}$ & 9800 & 9800 \\
\hline Saturation & & 1.0 & 1.0 \\
\hline 2D flow & $\mathrm{m}^{2} / \mathrm{s}$ & 0.01 & 0.01 \\
\hline Liquid viscosity & $\mathrm{Pas}$ & 0.001 & 0.001 \\
\hline
\end{tabular}

\subsection{Simulation Results and Analysis}

The following conclusions were drawn from the simulation results:

(1) The cracking location of the hydraulic fracturing in the multi-layered coal seam was always in the soft coal layer. When the depth was $300 \mathrm{~m}$, the initiation pressure of the multi-layered coal seam was $12.6 \mathrm{MPa}$. When the depth reached $800 \mathrm{~m}$, the initiation pressure was $27.5 \mathrm{MPa}$, which marks an increase of 2.2 times. Figure 11 shows the variation of the initiation pressure of the multi-layered coal seam under different depths and geo-stress states. As can be seen, the initiation pressure of the multi-layered coal seam linearly increased with the increase of the coal seam depth. As shown in Figure 11, the theoretical calculation results are in good agreement with the numerical simulation results.

(2) The hydraulic fracturing cracks occurred along the $X$ direction (minimum principal stress direction) in the soft coal layer, and propagated along the $\mathrm{Z}$ direction (maximum principal stress direction), without penetrating the hard coal layer. The direction of hydraulic fracture propagation in multi-layer coal seams is consistent with that of single coal seam. The half width of the fracture was approximately $0.02 \mathrm{~m}$ at different coal seam depths, when the water injection time was $20 \mathrm{~s}$. When the water injection time reached $300 \mathrm{~s}$, the half width of the fracture in the multi-layered coal seam with a simulated depth of $300 \mathrm{~m}$ was $0.033 \mathrm{~m}$, and the half width of the fracture in the multi-layered coal seam with a simulated depth of $800 \mathrm{~m}$ was $0.063 \mathrm{~m}$ (Figure 12). As the burial depth and three-dimensional geo-stress increased, the width of the hydraulic fractures in the soft layer of the multi-layered coal seam significantly increased. The research results are similar with the rules shown in Reference [35]. 


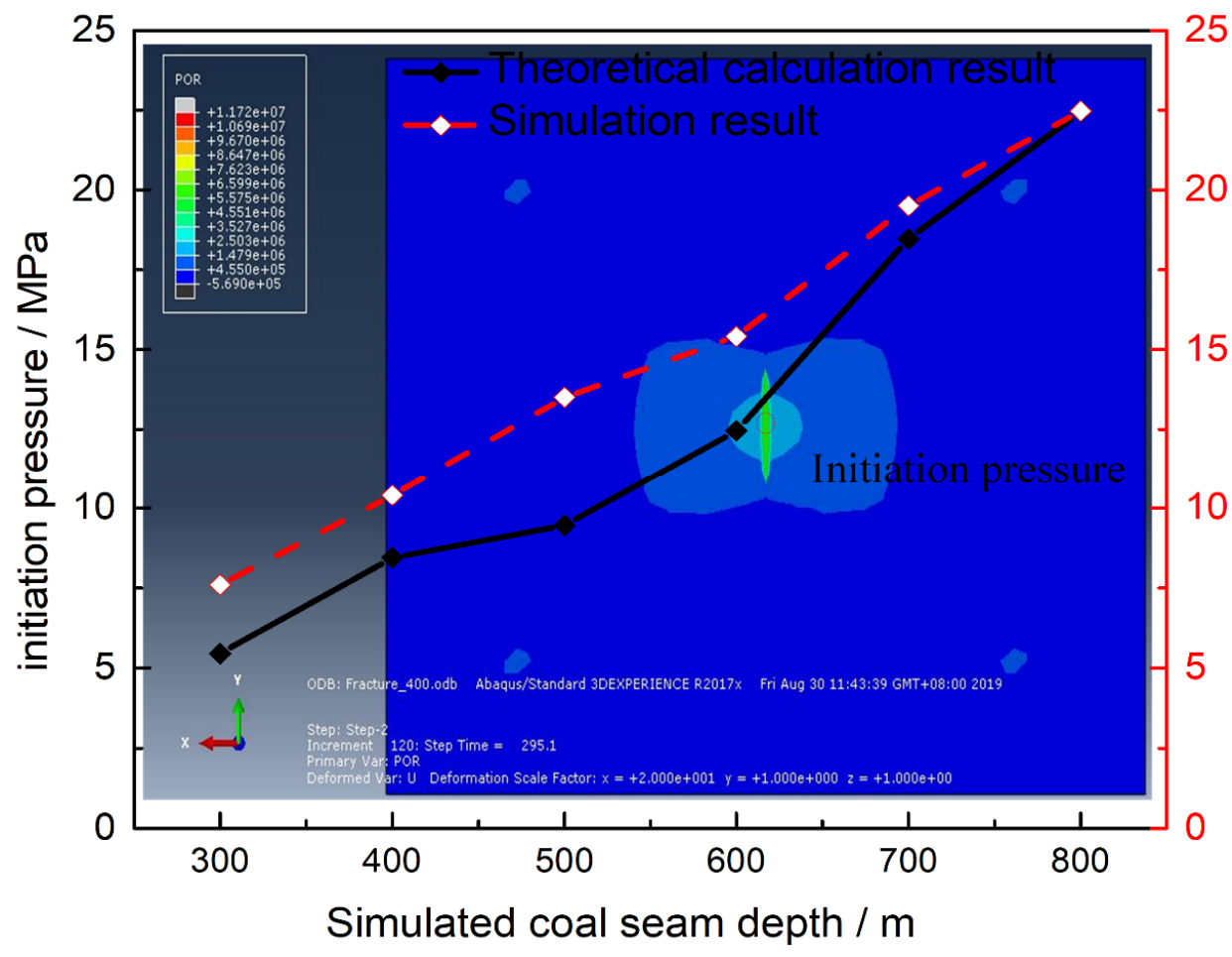

Figure 11. Initiation pressure of multi-layered coal seam.

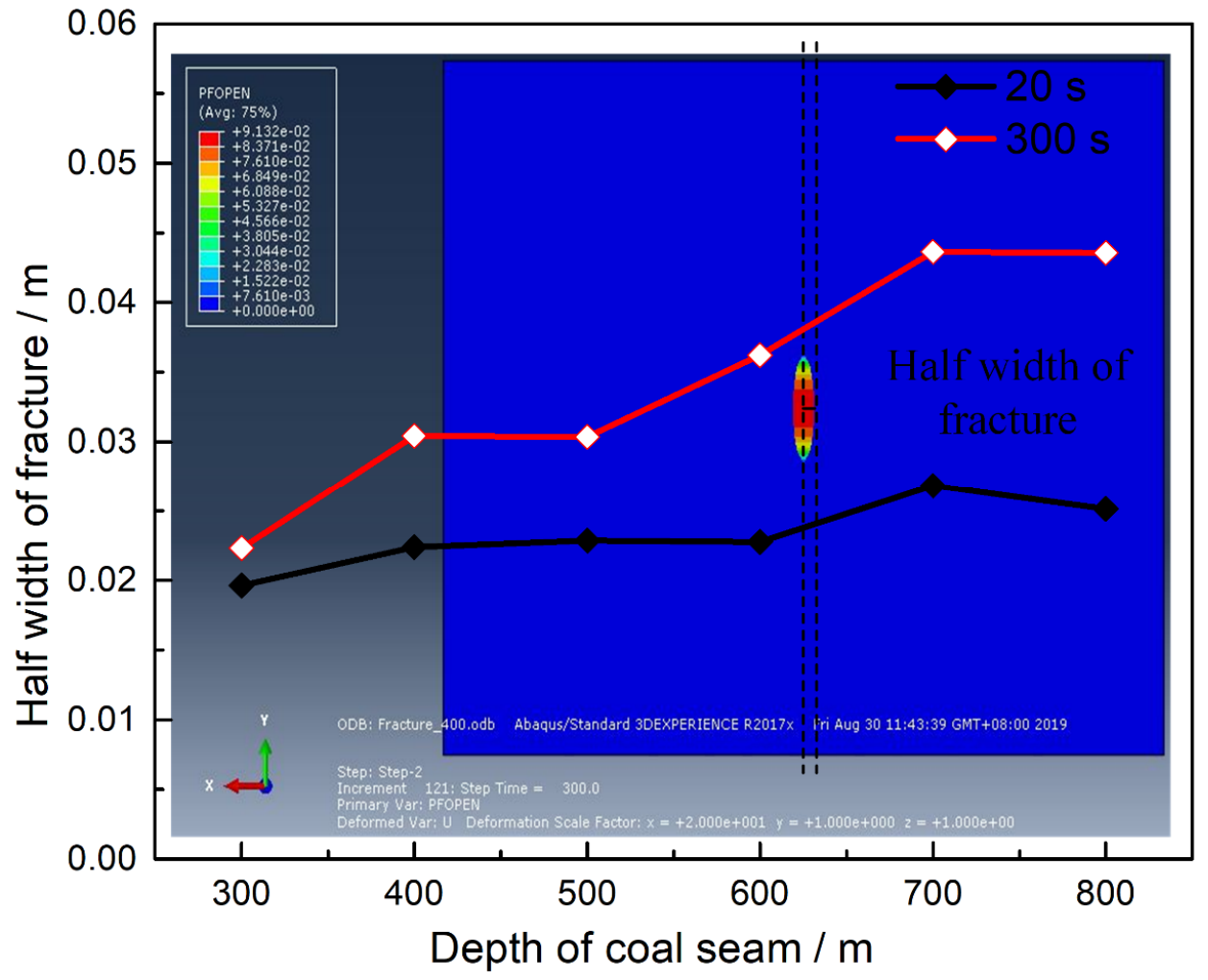

Figure 12. Half width of fracture in multi-layered coal seam.

\section{Conclusions}

In this study, the minimum crack initiation pressure of a multi-layered coal seam was theoretically derived. Additionally, a triaxial hydraulic fracturing simulation experiment for the multi-layered 
coal seam was carried out to verify the accuracy of the theoretical model, and a three-dimensional multi-layered coal seam model was established to investigate the hydraulic fractures.

The calculation model of the initiation pressure was established with consideration to factors such as the in-situ stress, tensile strength, and coal seam inclination of the multi-layered coal seam. The calculation and simulation experiment results reveal that the in-situ stress conditions had a significant impact on the initiation pressure for the hydraulic fracturing of the multi-layered coal seam.

At the coal seam inclinations of $0-50^{\circ}$ and depths of $300-800 \mathrm{~m}$, the initiation pressure did not change with the change of the coal seam inclination angle, and the initiation pressure linearly increased with the burial depth. The experimental results are consistent with the theoretical calculation results.

The fracture initiation location of the hydraulic fracture cracks in the multi-layered coal seam was located in the soft coal layer and extended along the maximum principal stress direction. As the dip angle increased, the hydraulic fracturing cracks in the multi-layered coal seam transitioned from complex fracture networks to single main fractures.

Author Contributions: Investigation, X.L.; Methodology, Z.Z.; Writing—original draft, S.C.; and Writing—review and editing, Y.W. and H.D. All authors have read and agreed to the published version of the manuscript.

Funding: This research was funded by National Natural Science Foundation of China (NSFC), grant numbers: 51774055, 51625401 and 51804050, the China Postdoctoral Science Foundation (2019T120810).

Acknowledgments: We thank Liwen Bianji, Edanz Editing China (www.liwenbianji.cn/ac), for editing the English text of a draft of this manuscript.

Conflicts of Interest: The authors declare no conflict of interest.

\section{References}

1. Wang, H.F.; Cheng, Y.P.; Yuan, L. Gas outburst disasters and the mining technology of key protective seam in coal seam group in the Huainan coalfield. Nat. Hazards 2013, 67, 763-782. [CrossRef]

2. Díaz Aguado, M.B.; González Nicieza, C. Control and prevention of gas outbursts in coal mines, Riosa-Olloniego coalfield, Spain (Article). Int. J. Coal Geol. 2007, 69, 253-266. [CrossRef]

3. Lin, B.Q. Mine Gas Control Theory and Technology; China University of Mining and Technology Press: Xuzhou, China, 2010.

4. Karacan, C.O.; Ruiz, F.A.; Cote, M.; Phipps, S. Coal mine methane: A review of capture and utilization practices with benefits to mining safety and to green-house gas reduction. Int. J. Coal Geol. 2011, 86, 121-156. [CrossRef]

5. Xia, T.; Zhou, F.; Liu, J.; Gao, F. Evaluation of the pre-drained coal seam gas quality. Fuel 2014, 130, $296-305$. [CrossRef]

6. Bredehoeft, J.; Wolff, R.; Keys, W.; Shuter, E. Hydraulic fracturing to determine the regional in situ stress field, piceance basin, colorado. Geol. Soc. Am. Bull. 1976, 87, 250-258. [CrossRef]

7. Abou-Sayed, A.; Brechtel, C.; Clifton, R. In situ stress determination by hydrofracturing: A fracture mechanics approach. J. Geophys. Res. Part B Solid Earth 1978, 83, 2851-2862. [CrossRef]

8. Fan, T.; Zhang, G.; Cui, J. The impact of cleats on hydraulic fracture initiation and propagation in coal seams. Pet. Sci. 2014, 11, 532-539. [CrossRef]

9. Hubbert, M.K.; Willis, D.G. Mechanics of hydraulic fracturing. Dev. Pet. Sci. 1972, 210, 369-390.

10. Dunlap, I.R. Factors controlling the orientation and direction of hydraulic fractures. Soc. Pet. Eng. 1962, $49,282-288$.

11. Zhang, G.H.; Wei, G.P.; Hou, F.C. The theory of water injection pressure and cracking position of fractured layer drilling. J. Coal 2007, 32, 52-55.

12. Lu, Y.C. Application of hydraulic fracturing technology in high gas and low permeability mines. J. Chongqing Univ. 2010, 33, 102-107.

13. Schmitt, D.; Zoback, M. Poroelastic effects in the determination of the maximum horizontal principal stress in hydraulic fracturing tests-A proposed breakdown equation employing a modified effective stress relation for tensile failure. Int. J. Rock Mech. Min. Sci. Geomech. 1989, 26, 499-506. [CrossRef]

14. Schmitt, D.R.; Currie, C.A.; Zhang, L. Crustal stress determination from boreholes and rock cores:Fundamental principles. Tectonophysics 2012, 580, 1-26. [CrossRef] 
15. Bohloli, B.; de Pater, C.J. Experimental study on hydraulic fracturing of soft rocks: Influence of fluid rheology and confining stress. J. Pet. Sci. Eng. 2006, 53, 1-12. [CrossRef]

16. Holditch, S.A. Enhanced recovery of Coalbed Methane through hydraulic fracturing. In Proceedings of the SPE Annual Technical Conference and Exhibition, Houston, TX, USA, 2-5 October 1988; pp. 1-9.

17. Zhou, J.; Chen, M.; Jin, Y.; Zhang, G.Q. Analysis of fracture propagation behavior and fracture geometry using a tri-axial fracturing system in naturally fractured reservoirs. Int. J. Rock Mech. Min. Sci. 2008, 45, 1143-1152. [CrossRef]

18. Chang, H. Hydraulic Fracturing in Particulate Materials. Ph.D. Thesis, Georgia Institute of Technology, Atlanta, GA, USA, 2004.

19. Jiang, T.; Zhang, J.; Wu, H. Experimental and numerical study on hydraulic fracture propagation in coalbed methane reservoir. J. Nat. Gas Sci. Eng. 2016, 35, 455-467. [CrossRef]

20. Wang, Y.; Tonon, F. Modeling Lac du Bonnet granite using a discrete element model. Int. J. Rock Mech. Min. Sci. 2009, 46, 1124-1135. [CrossRef]

21. Barati, R.; Liang, J.T. A review of fracturing fluid systems used for hydraulic fracturing of oil and gas wells. J. Appl. Polym. Sci. 2014, 131, 40735. [CrossRef]

22. Wang, T.; Hu, W.; Elsworth, D.; Zhou, W.; Zhou, W.; Zhao, X.; Zhao, L. The effect of natural fractures on hydraulic fracturing propagation in coal seams. J. Pet. Sci. Eng. 2017, 150, 180-190. [CrossRef]

23. Zhang, X.; Jeffrey, R.G.; Bunger, A.P. Initiation and growth of a hydraulic fracture from a circular wellbore. Int. J. Rock Mech. Min. Sci. 2011, 48, 984-995. [CrossRef]

24. Huang, J.S.; Griffiths, D.V.; Wong, S.W. Insitu stress determination from inversion of hydraulic fracture data. Int. J. Rock Mech. Min. Sci. 2011, 48, 476-481. [CrossRef]

25. Huang, J.S.; Griffiths, D.V.; Wong, S.W. Initiation pressure, location and orientation of hydraulic fracture. Int. J. Rock Mech. Min. Sci. 2012, 49, 59-67. [CrossRef]

26. Zhang, G.H.; Wei, G.P.; Hou, F.C. Theory of start-split affusion stress and start-split location about through coal delam inaions' bore of hydraulic fracture. J. China Coal Soc. 2007, 32, 52-55.

27. Deng, G.Z.; Huang, B.X.; Wang, G.D. Theoretical analysis of pressure parameters for water pressure expansion of circular hole wall cracks. J. Xi'an Inst. Sci. Technol. 2003, 23, 361-364.

28. Defuel, L.; Clark, J. Hydraulic fracture propagation in layered rock: Experimental studies of fracture containment. Int. J. Rock Mech. Min. Sci. Geomech. Abstr. 1981, 24, 19-32.

29. Crosby, D.G.; Rahman, M.M.; Rahman, M.K. Single and multiple transverse fracture initiation from horizontal wells. J. Pet. Sci. Eng. 2002, 35, 191-204. [CrossRef]

30. Shimizu, H. Distinct Element Modeling for Fundamental Rock Fracturing and Application to Hydraulic Fracturing. Ph.D. Thesis, Kyoto University, Kyoto, Japan, 2010.

31. Chen, M.; Zhang, G.Q. Petroleum Engineering Rock Mechanics; Science Press: Beijing, China, 2008.

32. Jin, Y.; Chen, M.; Zhang, X.D. Hydraulic fracturing initiation pressure models for directional wells in naturally fractured formation. J. Pet. 2006, 27, 124-126.

33. Zhang, G.H.; Liang, B.; Sun, G.Y. Analysis of the initial crack location and development process of coal seam along the borehole. J. China Coal Soc. 2005, 30,34-37.

34. Li, D.Q.; Zhang, S.C.; Zhang, S.A. Experimental and numerical simulation study on fracturing through interlayer to coal seam. J. Nat. Gas Sci. Eng. 2014, 21, 386-396. [CrossRef]

35. Zhang, G.M.; Liu, H.; Zhang, J. Three-dimensional finite element simulation and parametric study for horizontal well hydraulic fracture. J. Pet. Sci. Eng. 2010, 72, 310-317. [CrossRef]

(C) 2020 by the authors. Licensee MDPI, Basel, Switzerland. This article is an open access article distributed under the terms and conditions of the Creative Commons Attribution (CC BY) license (http://creativecommons.org/licenses/by/4.0/). 